\title{
Air Navigation Services in Australia and the United States: A Comparative Case Study
}

\author{
Roxanne Zolin \\ Queensland University of Technology, Australia \\ E-mail: r.zolin@qut.edu.au \\ Ira Lewis \\ Naval Postgraduate School \\ E-mail: ialewis@nps.edu
}

Received: March 18, 2014 Accepted: May 2, 2014 Published: May 27, 2014

doi:10.5296/csbm.v1i1.5312ＵRL: http://dx.doi.org/10.5296/csbm.v1i1.5312

\begin{abstract}
Air Navigation Services (ANS) are, by their very nature, international and this creates internationally comparative strengths and weaknesses, opportunities and threats. This case study compares two very different countries, Australia and the United States. This case study asks how do differences between Australia and the United States in context, cultures, institutions and organizations interact to result in differences in ANS offered in these two countries.
\end{abstract}

Keywords: Governance, Innovation, Air navigation services, Business systems, International 


\section{Introduction}

Air Navigation Services (ANS) are, by their very nature, international and this creates internationally comparative strengths and weaknesses, opportunities and threats. This case study compares two very different countries, Australia and the United States. This case study asks how do differences between Australia and the United States in context, cultures, institutions and organizations interact to result in differences in ANS offered in these two countries.

\section{Background}

The central document governing the global organization of ANS is the Convention on International Civil Aviation, commonly referred to as the "Chicago Convention," whose original version was signed in that city in 1944. In the Convention, Contracting States agreed to ensure the minimum standards of ANS established by ICAO, a specialized United Nations agency created by the Convention (International Civil Aviation Organization, 2000).

Emanating from obligations under the Chicago Convention, ANS has traditionally provided by departments of national governments. However, there is a widespread trend toward transferring delivery of ANS services outside of line departments of national governments to independent agencies or corporations. The Civil Air Navigation Services Organisation (Note 1) (CANSO), which is the trade association for independent ANS providers, currently counts approximately 60 members, and is steadily growing.

However, whatever delivery mechanisms are chosen, national governments remain ultimately responsible for ensuring that adequate ANS services are available. The provision by governments of ANS reflects the responsibility of the state for safety, international relations, and indirectly, the macroeconomic benefits of ensuring a sound infrastructure for aviation. ANS is a "public good" and an "essential good" provided to all aircraft using a country's airfields and airspace. However, ANS also represents a service that directly benefits only a limited number of users, notably aircraft owners and operators.

The idea that the users of the system, rather than the taxpaying public, should incur the costs associated with ANS provision is inherent in the commercialization process. However, ICAO sets out broad principles for the establishment of user charges, which member states are expected to comply with. ICAO states that only distance flown and aircraft weights are acceptable parameters for use in a charging system. These two factors are considered to be easy to measure, bear a reasonable relationship to the value of service received, and do not discriminate due to factors such as where the flight originated or the nation of aircraft registration.

\section{The Challenges of Air Navigation Services "Down Under”}

Australia is typically described as the "island continent" located "down under." With a land mass of approximately 2,966,136 square miles, $10 \%$ smaller than the continental United States, Australia is many things: a single country operating under a parliamentary form of government partially based on that of the United Kingdom, a federal nation inspired by the 
U.S., and located on the world's largest island and smallest continent.

Located in Southeast Asia, Australia's closest neighbors are Papua New Guinea and East Timor on the north, Indonesia to the north-west and New Zealand to the south-east; all of these countries (except New Zealand, which only had some serious economic difficulties in the 1980s) have shown instability in the post-World War II period and are a continuing source of concern for Australians. The airspace managed by Airservices Australia (Note 2) (AA) represents approximately $11 \%$ of the world's surface. AA provides air navigation services for some of its neighboring countries and over much of the ocean in Southeast Asia.

Like Americans, Australians mostly speak English and enjoy a high standard of living. The population of Australia at the 2001 census was 18,972,350 (Note 3), compared to an estimated 299,243,413 in the United States in 2006 (Note 4).

Possibly due to Australia's large size and small, scattered population, aviation has been very important to Australia's industry and growth. The two major export industries of Australia rely heavily upon commercial and general aviation: mining and agriculture. To service small populations in remote towns and stations Australia has developed creative aviation services, such as the Royal Flying Doctor Service, established in 1928 to provide emergency medical aid to the people of the "Outback," and comprehensive health care and community service.

Although hit by international trends such as the Asian economic crisis of the 1990s and the effects of $9 / 11$, Australian aviation is growing with an $11 \%$ increase in regional traffic in 2004 (Note 5).

\subsection{Airservices Australia}

During the 1970s, Australia began moving away from the traditional government department form of organization toward more creative options for the provision of air navigation services. In 1975 the Department of Civil Aviation (DCA) was merged with the Department of Transportation, but in 1990 the Civil Aviation Authority, similar to the FAA, was formed. In 1990 the Civil Aviation Safety Authority (CASA) was formed and most regulatory functions of the CAA were transferred to CASA. Airports were split off and then privatized through leasing. For example the Sydney airport is owned by the federal government but the Sydney Airport Corporation Ltd., part of the Southern Cross Airports Corporation Holdings Limited group, has a 99 year lease, which gives it close to a monopoly position. In 1995 Airservices Australia (AA) was created as a government authority with a board of directors to manage air navigation services. During 1997, AA underwent an overhaul aimed at reducing costs and charges by $25 \%$ and increasing profitability, goals that were achieved in just three years.

Airservices Australia is different from the FAA in that they do not have responsibility for regulating air navigation services, but they are allowed to charge for them. Moves are currently being undertaken to move the remaining few regulatory activities from AA over to CASA. As one AA manager explained, having air traffic management and regulation in the same organization can create a conflict of interests: "You are asking someone in the organization to oversee the bloke down the hall.” 
Australia has been a world leader in implementing new air navigation technology. AA technology personnel reflected on conditions in CAA, prior to the creation of AA a new Air Navigation Services system that was commissioned in 1975 was delivered about 1985. In comparison, in 1998 AA has introduced The Australian Advanced Air Traffic System (TAAATS), which provides a single uniform system for all phases of ANS - en route, oceanic, continental non-radar and radar, terminal area and control tower. In 2006 AA launched Flex Tracks, which represent an evolution from pre-published flight routes toward daily calculated "user preferred" flight routes that minimize headwind and maximize tail winds.

The International Air Transport Association, which represents the world's major carriers, estimates that based upon an average operating cost of $\$ 100$ per minute, a reduction of 1 minute of scheduled air transport operation across the globe would save the industry \$3 billion annually. Flex Tracks are actually based upon a U.S. system created by the FAA, the Dynamic Ocean Track System Plus (DOTS+), used to parallel air routes to handle heavy traffic loads. Using the DOTS+ platform, AA developed the Australian Organized Track Structure for Flex Tracks that integrates international and domestic routes.

At the same time Australia is also working toward installing the Automatic Dependent Surveillance Broadcast (ADS-B) across the whole continent above 30,000 ft to reduce the separation standards for suitably equipped aircraft to just $5 \mathrm{~nm}$ when two thirds of the continent does not have radar. ADS-B has the potential to replace radar with a global positioning system in which an aircraft broadcast its position, which is relayed by transponders to other craft and Air Navigation Services towers. Radar installations costing $\$ 10,000,000$ each could be replaced by transponders costing $\$ 300,000$ each.

With about 27 transponders Australia could provide ANS across the whole continent. The ADS-B system allows aircraft to watch out for other craft in their area, reducing the workload on control towers, which have become a bottleneck in the system. The ADS-B technology was developed by the FAA and used in the CAPSTONE demonstration installation in Alaska, but appears to be a long way from adoption across the wider U.S. In 2006, AA announced a plan to introduce more accurate navigation systems based on satellites.

The Ground-Based Augmentation Systems (GBAS) replaces instrument landing systems for precision approaches at major airports. The Ground-Based Regional Augmentation Systems (GRAS) will to provide regional coverage for enroute navigation and approaches with vertical guidance for smaller commercial and General Aviation (GA) aircraft. The two systems are available with one avionics box and support the ADS-B broadcast system. AA is working closely with avionics manufactures and pilot training to ensure they are ready to participate in the new technology when it becomes available.

\subsection{The Commercial Airline Story: Qantas}

Qantas, which stands for “Queensland and Northern Territory Aerial Services Limited” is Australia's largest airline. Qantas is famous for being mentioned by Dustin Hoffman in the award winning movie, "Rain Man,” for having the best safety record of any major airline in 
the world. Including its low-cost subsidiary, Jetstar, and the recent takeover of Australian Airlines, Qantas dominates Australian civil aviation.

A high ranking Qantas representative with many years of air navigation experience provided a balanced but positive view of their relationship with Airservices Australia. AA was perceived to be much like the FAA, i.e. a large government bureaucracy and a "comfortable place to work," but AA was also considered to have maintained the tradition of being a "premiere government department" with a culture of pride, originally employing ex-WWII fighters and a strong culture of pilots and esprit de corps.

Despite general approval of the separation of regulation and service into CASA and AA, there were some concerns. Although privatization of airports is done by leasehold, it is a monopoly because the airport corporations hold 99 year leases which are not up for renewal. As the Qantas representative said, “They can charge what they like, and they do!”

The Qantas executive also thought that AA should be treated like an airline and required to renew their license depending upon performance, subject to audits, scrutiny and regulation. He also favored bringing in more competition. "Start with control towers, the aerodrome owner is responsible, not expertise, they should be able to engage AA or put out to tender." For example, AA is in business of providing tower services to the US and has three control towers in the Pacific with a class D, 5 year contract. Another Qantas executive pointed out that under the current system there is no incentive for $3^{\text {rd }}$ parties to spend any capital. It was also pointed out that absence of competition is now the current culture.

On the positive side, the Qantas executives thought that collaboration between AA, industry and the Department of Transport and Regional Services was very good. The collaborative Air Traffic Management Strategic Planning process, which started in 1983, allowed the creation of a mature future vision for the years up to 2025, with all working together on implementation.

Despite criticisms of the AA monopoly, Qantas would not like to return to the wholly government run DCA, but would like to see more checks and balances on the power of AA. Recently Qantas was granted a price freeze in the face of a large proposed price increase. They would also like to see a slowdown in cutbacks because a lot of corporate history is being lost in the reorganization. With too many new people the mistakes of the past may be revisited.

\subsection{Military Air Navigation Services}

A military perspective was provided by a Military Representative within the Department of Transport and Regional Services, who had 30 years experience in military aviation. When asked about the creation of AA he said that Australia should have stuck with DCA. From this perspective DCA had provided a single POC for the Department of Defence for civil-military coordination of all aviation matters, including policy, management, and airspace safety regulation.

As an example the officer asked "What if you took the Department of Main Roads and made 
every road privatized and had a toll for every road? Back in the 1950's the Airspace Coordination Committee was formed to consider strategic issues of civilian - military airspace. This organization has recently been disbanded and Defence has to interact with AA over operations, DOTARS over civilian to military transfer policy, and CASA over safety regulation. Flexible use of airspace is perceived to become more and more difficult.

In Australia, as in most countries except Switzerland, there are two totally different aviation authorities; civil and military. The military has its own airspace, airports, legislation and ability to make airspace regulations. The Chief of the Defence Force, Australia's only four-star officer, coordinates Australia's three military services with respect to ANS and the military can designate areas as restricted to civil aviation.

For example the Royal Australian Air Force (RAAF) controls the airports of two major cities, Darwin and Townsville. Having two independent systems requires an interface to allow for civilian transit through military airspace. This is problematic due to the differences between military and ICAO regulations. The level of acceptable risk is much lower for civilian than for military aircraft. For example military planes are allowed to fly with smaller fuel reserves, 3 minutes compared to 45 minutes for civilian aircraft. Transit of civilian aircraft through military airspace is limited in time duration and number for security and safety reasons.

The current system requires a civilian aircraft to request permission in the air to transit military airspace. If permission is denied due to military activities in the area the civilian aircraft must fly around the military airspace. Plans are afoot to provide civilian aircraft with ICAO standards of separation in military airspace, pre-organized transit through military airspace and standing authorizations for commercial aircraft, such as those of Qantas. Military aircraft flying in civilian airspace also encounter problems. Military supersonic planes, such as the altimeter can vary by $+/-1,000$ feet, requiring a much larger bubble of separation than afforded by ICAO standards.

Not all Australian ANS innovations have come to fruition. In 2003 the Minister for Transport and Regional Services announced a study into the potential merging of Australia's military and civil air traffic management systems to cut duplication and costs. While some progress has been made, little has changed so far. However, in 2006 the RAAF and Airservices Australia did announce a first step towards integration with all military and commercial ANS for the Perth area in Western Australia to be provided from a single facility (Civil Air Navigation Services Organisation, 2006).

\subsection{General Aviation}

General Aviation (GA) refers to the many individuals, companies and not for profit organizations, which operate aircraft for their own purposes. In Australia the interests of these groups are represented by the Aircraft Owners and Pilots Association of Australia (AOPA), which is a member of the International Council of Aircraft Owners and Pilots Association (IAOPA). AOPA is a not for profit organization, whose primary mission is advocacy to "ensure pilots and aircraft owners are free to fly without unnecessary restrictions or costs." 
When asked about AA a representative of AOPA said that there were "Too many costs, not enough promotion and too much regulation.” The representative said that pilots and owners should only pay for services that they use. For example they do not want to pay for radar in the Sydney basin when they are flying around the outskirts of Sydney. Similarly, why should farmers pay a tax on airplane fuel for ANS when they fly in outback areas that do not have radar? AOPA was not represented on the AA Board, which was perceived to represent "retired airline pilots" rather than the user organizations like AOPA. Interestingly enough AOPA preferred not being on the Board of AA to "fight from the outside" and better exercise its advocacy role.

The comment was made by AOPA that CASA should be the "Civil Aviation Development and Safety Association”. In other words there should be a strong emphasis on promoting the aviation industry. It appears as though the GA community does not see a lot of distinction between the government department, DOTARS, AA and CASA. Although AA is perceived as more customer orientated than CASA, providing high quality services, it is also perceived as being highly basically an arm of the Government and highly unionized. CASA is seen as "not in the $21^{\text {st }}$ century" and needing to be more user-friendly "not police, but open to industry input.” The AOPA representative complained about CASA's security checks on airline captains and proposed that the industry could do a better job than CASA through self-regulation.

\section{Air Navigation Services in the United States}

The United States, with a population of almost 300 million people, is the largest domestic and international air travel market in the world and is characterized by a remarkable density of air traffic around many of its metropolitan areas. In contrast to Australia, the U.S. continues to both regulate and deliver ANS services through the Federal Aviation Administration (FAA), a bureau of the U.S. Department of Transportation. The FAA is the direct descendant of the Aeronautics Branch of the U.S. Department of Commerce, created in 1926. However, the FAA does benefit from a somewhat greater degree of flexibility in personnel management and procurement than other U.S. government agencies (U.S. General Accounting Office, 2003a). Also, private firms operate a small number (currently 69) of towers at low-volume airfields. Adversaries of the "contract towers" program view it as a harbinger of widespread privatization of the FAA (Hugnes, 2005).

The FAA's challenges in modernizing its infrastructure have been a key driver of proposals for reform. Antiquated and unreliable equipment, an aging workforce, and resistance to change have been cited as the key barriers to effective FAA performance of the ANS function. Additionally, the FAA has a poor track record in managing large, technology-intensive capital projects (See note 6.).

Prior to the creation of NAVCANADA, the Canadian equivalent of Airservices Australia, in 1996, a similar difficulty with the management of capital investment prevailed with the management of large-scale ANS projects by Canada's Department of Transport. Indeed, improved management of technology has been cited as one of the key accomplishments of NAVCANADA since its creation in 1996 Civil Air Navigation Services Organisation, 1999), 
in the same vein as Airservices Australia's success with ADS-B described above.

Restructuring of ANS in the United States was first proposed in 1993 as part of the National Performance Review (Poole and Butler, (2001). Reform has not been possible, despite unsuccessful attempts in 1995 and 1998 by the Clinton administration to promote legislation creating a government corporation somewhat like NAVCANADA, an option known as “corporatization." (Treanor, 1998). Since then, there has been little discussion of restructuring of ANS services in the U.S. The U.S. attempts at reform have been described as follows in a 1999 article:

The Clinton Administration has repeatedly tried to tinker with the structure of the FAA, and three years ago freed the agency from many Federal constraints on personnel and procurement policy. Last year, the Administration proposed making the FAA a "performance-based organization" like the Patent and Trademark Office, which sets its own fees and controls its revenues, but Congress did not agree. Members of Congress enjoy their leverage over the FAA, bringing home bacon to their constituents in the form of instrument landing systems, new runways and the like.”(Wald, 1999)

However, during 2003, the FAA did announce an internal reorganization that groups the major functions that support ANS, such as procurement and financial management, under an Air Traffic Organization, rather than having them scattered throughout the FAA (Bond, David 1999). This reorganization is consistent with the 1997 recommendations of the National Civil Aviation Review Commission, which proposed a "performance based organization" within the FAA to manage ANS. However, the reorganization announced in 2003 does not incorporate one of the key recommendations of the Commission report, the creation of a board to manage the new organization, similar to that of Airservices Australia.

The U.S. remains the only major nation in the world that does not charge ANS fees to aircraft operators and that also continues to run ANS under the traditional government department structure. The sole exception is fees charged to aircraft that overfly the U.S. without taking off or landing. A further attempt at reforming ANS and moving towards a revenue-based structure was announced by the FAA in March 2006 but immediately attacked by the GA community as an attempt to cross-subsidize U.S. airlines and help them with their well-known financial problems.

The (U.S.) Aircraft Owners and Pilots Association counts over 400,000 members and is considered a formidable GA lobby group in Congress. The major carriers naturally supported the proposal, as they saw ANS fees (charged by almost every other nation) as inevitable, and the FAA proposal as an opportunity to share the cost of the system with other operators. With Congress having a heavy workload to contend with in the foreseeable future, major ANS reform in the U.S. remains unlikely (Wald, 1999).

Given the size and complexity of ANS operations in the U.S., the close relationship of ANS to other national security functions, and opposition from unions and members of Congress, significant changes to the governance of ANS functions are perhaps unlikely. 


\section{The FAA-DOD Relationship}

The relationship between the FAA and the U.S. Department of Defense (DOD) is extremely complex, given the volume and number of aircraft in both the military and civil domains. Part of the challenge in describing this relationship is the size and complexity the U.S. armed services, which dwarf the Australian Defence Force in size. The FAA is responsible for managing an integrated system of civil and military ANS throughout the U.S., while the military provides ANS to cover airfields and airspace directly under military jurisdiction. DOD provides about 20 percent of ANS in the U.S. (MITRE, 2000).

The attacks of September 11, 2001 provoked a major re-examination of FAA's relationship with DOD, with a strong emphasis on better liaison and shared procedures. The FAA is currently developing a national plan for the nation's airspace through 2025, in cooperation with DOD, the Department of Homeland Security, the National Aeronautics and Space Administration, and the Department of Commerce. The creation of U.S. Northern Command as a coordinating body for the military's support to homeland security has also provided a central DOD point of contact for liaison with other federal agencies, including the FAA (Note 6).

\section{Case Study Questions}

As you have read above, there are a range of organizational structures used through the world for the provision of air navigation services. The case focuses on two of these, a restructured government agency managed by a board of directors (Airservices Australia) and a traditional government agency (the FAA's Air Traffic Organization). The objective of this case study is to gain a deeper understanding into the advantages of alternative organizational structures along the public to private continuum.

The following questions are provided to guide your analysis and discussion:

1) From the U.S. perspective, what might be the advantages or disadvantages of a government agency with a board of directors, similar to Airservices Australia compared to the existing structure of the FAA?

2) Should the FAA change its organization structure? If so, where should the FAA be placed along the public to private continuum?

3) If the FAA were to move in the direction of increased privateness, what might be the technical, social, economic and political pressures for or against such an organizational change?

4) What organizational change strategies might you suggest?

In addressing the case, you may wish to refer to the materials provided in the reference list.

\section{References}

Bond, David. (1999). Departure Point, Aviation Week \& Space Technology, 33-35. C CANSO News. (2006). Civil Air Navigation Services Organisation, CANSO News, 28, July 
2006, 4.

Hughes, David. (2005). House OKs FAA Bill But Republican Change to Legislation Doesn't Satisfy Democrats on ATC Privatization. Aviation Week \& Space Technology, 54-55.

International Civil Aviation Organization. (2000). Convention on International Civil Aviation. Eighth Edition (Document 7300/8).

Lewis, Ira \& Roxanne Zolin (2004). The Public to Private Continuum Measure and the Role of Stakeholder Boards as a Proxy for Markets in the Governance of Air Navigation Services. International Public Management Review, 5(2).

Lewis, Ira. (2004). Analysis of Alternative Institutional Arrangements for Reform of U.S. Air Traffic Control. International Public Management Journal, 7(3) 385-414.

MITRE. (2000). Annual Report, section “Improving Global Air Travel”.

Poole, Robert \& Butler, Viggo (2001). How to Commercialize Air Traffic Control, February, Reason Public Policy Institute, Policy Study No. 278. Retrieved from http://www.rppi.org/ps278central.html

Treanor, J. L. (1998). Privatization v. Corporatization of the Federal Aviation Administration: Revamping Air Traffic Control. The Journal of Air Law and Commerce, 63(3), 633-680.

U. S. General Accounting Office. (2003a). Federal Aviation Administration: Reauthorization Provides Opportunities to Address Key Agency Challenges, April 10 (GAO-03-653T).

U.S. Department of Transportation, Federal Aviation Administration, Air Traffic Organization. Retrieved from http://www.ato.faa.gov/

Wald, Matthew L. (1999). Sale of Air Traffic System Has Led to Technical Advances. The New York Times, October 23.

\section{Notes}

Note 1. Civil Air Navigation Services Organization, http://www.canso.org 10/03/06

Note 2. Airservices Australia, http://www.airservicesaustralia.com 10/03/06

Note 3.

http://www.abs.gov.au/websitedbs/d3310114.nsf/51c9a3d36edfd0dfca256acb00118404/a744 423136eac75bca257161000a3760!OpenDocument

Note 4. http://factfinder.census.gov/home/saff/main.html?_lang=en

Note 5. http://www.alga.asn.au/policy/transport/congress/2005/download/brianCandler.ppt

Note 6. Statement By Mr. Paul McHale, Assistant Secretary of Defense for Homeland Defense before the Subcommittee on Readiness, House Armed Service Committee, United States House of Representatives, March 13, 2003, http://www.house.gov/hasc/openingstatementsandpressreleases/108thcongress/03-03-13mcha le.html 


\section{Copyright Disclaimer}

Copyright reserved by the author(s).

This article is an open-access article distributed under the terms and conditions of the Creative Commons Attribution license (http://creativecommons.org/licenses/by/3.0/). 